\title{
Roles for literature in medical education
}

\author{
Martyn Evans
}

\begin{abstract}
The sustained study of literary texts and, to a lesser extent, of techniques of literary analysis offers a number of educational 'goods' to the medical curriculum, to medical students and to the clinical practitioners they will one day become. In addition to the intrinsic goods of literature - the intense and direct experience of connecting with another's vision of the world - there are 'instrumental' goods augmenting the clinician's necessary physical understanding of patients' bodies with the equally necessary personal understanding of patients as individuals. These goods include (within the context of a medical curriculum genuinely located in higher education rather than in mere training) skills of communication, sensitive appreciation of the ethical dimensions of practice, the development of students' personal values and the stimulation of an enduring sense of wonder at embodied human nature.
\end{abstract}

\section{'Do you see it, young man?'}

'Do you see it, young man?' This is how the Hofrat (medical director) of the tuberculosis sanatorium situated on the slopes of Thomas Mann's Magic Mountain, invites Herr Hans Castorp, the book's flawed young hero, to gaze into the primitive fluoroscope image of his ailing cousin Joachim:

'And to the pulsation of the floor, and the snapping and cracking of the forces at play, Hans Castorp peered through the lighted window, peered into Joachim Ziemssen's empty skeleton. The breastbone and spine fell together in a single dark column. The frontal structure of the ribs was cut across by the paler structure of the back. Above, the collar-bones branched off on both sides, and the framework of the shoulder, with the joint and the beginning of Joachim's arm, showed sharp and bare through the soft envelope of flesh...

...But Hans Castorp's attention was taken up by something like a bag, a strange, animal shape, darkly visible behind the middle column, or more on the right side of it - the spectator's right. It expanded and contracted regularly, a little after the fashion of a swimming jellyfish.

"Look at his heart," and the Hofrat lifted his huge hand again from his thigh and pointed with his forefinger at the pulsating shadow. Good God, it was the heart, it was Joachim's honour-loving heart that Hans Castorp saw!' (1996 reprint: p. 127).

Set in the years leading up to the outbreak of the First World War, and written only a little later than the period in which it was set, this is effectively a contemporary account of the early appearance in the medical armoury of imaging technology - here, the fluoroscope - and the astounding impact it must have made on the layman encountering it for the first time. A 'witches' kitchen' is how Mann describes the whole imaging laboratory, complete with a 'private thunderstorm' of electrical discharges and glowing retorts.

Of historical interest, perhaps; but not only that. The teller of tales makes the tale come alive. Consider the shock and excitement of discovery - not only in a Wellsian technological past but right here and right now - of making the invisible become visible, of 'anatomising' the interior of a still-living body, a body just like your own in every important respect. Sometimes a carefully articulated image is used: he peered through the lighted window, he peered into Joachim Ziemssen's empty skeleton. Sometimes the sparest of prose is enough: Good God, it was the heart! The reader who has sat with Hans Castorp through his journey and arrival at the sanatorium - who has sat with him at the interminable meals and despaired of his artless efforts to impose youthful originality and independence upon suffocating bourgeois conversation - who has frequently wanted to strangle him and half the sanatorium's inhabitants - the reader who, in short, after 200 pages has stumbled upon the chapter called 'Sudden enlightenment' and feels himself sorely in need of it, now walks alongside Castorp, trembling, through the arched doors of Mann's arch prose into the Gothic vaults of the X-ray chamber; and now the reader steps, head spinning, up to the fluoroscope machine itself as if it were tomorrow's lurid

Martyn Evans is Professor of Humanities in Medicine at the Centre for Arts and Humanities in Health and Medicine, University of Durham (14/15 Old Elvet, Durham DH1 3HP, UK. E-mail: h.m.evans@durham.ac.uk). He is a philosopher, who from 1986 taught and researched in the philosophy and ethics of medicine at the University of Wales Swansea, having previously taken a doctorate in the philosophy of music. In July 2002, he was appointed as the first Principal of the new John Snow College at Durham University's Queen's Campus, Stockton-on-Tees. 
prophesy and not yesterday's medical commonplace. But much, much more:

'A few minutes later [Hans Castorp] himself stood in the pillory, in the midst of the electrical storm, while Joachim, his body closed up again, put on his clothes. Again the Hofrat peered into the milky glass, this time into Hans Castorp's own inside; and from his half-utterances, his broken phrases and bursts of scolding, the young man gathered that what he saw corresponded to his expectations. He was so kind as to permit the patient, at his request, to look at his own hand through the screen. And Hans Castorp saw precisely what he must have expected, but what it is hardly permitted man to see, and what he thought it would never be vouchsafed him to see: he looked into his own grave. The process of decay was forestalled by the powers of the light-ray, the flesh in which he walked disintegrated, annihilated, dissolved in vacant mist, and there within it was the finely turned skeleton of his own hand, the seal ring he had inherited from his grandfather hanging loose and black on the joint of his ring-finger - a hard, material object with which man adorns the body that is fated to melt away beneath it, when it passes on to another flesh that can wear it for yet a little while ... [With] penetrating, prophetic eyes, he gazed at this familiar part of his own body, and for the first time in his life he understood that he would die' (1996 reprint: pp. 218-219 (my italics)).

A passage like this either leaves you coldly unmoved or it stops your heart. To those left unmoved, I am afraid I probably have nothing interesting to say (unless it be to direct you elsewhere in this issue). But if for you, as for me, the ideas in this passage are as electrifying as the processes generating the vision of Hans's grave, and if for you this prose - even in the stilted English of the earliest published translation from the German - is itself a form of radiant, albeit spooky, illumination, then I will try to suggest how (and why) that illumination might be harnessed within medical education and the making of doctors, psychiatrists among them.

\section{Four medical educational 'goods' - and literature's support for them}

Let us take it as read that medical education must instil and refine the medical student's scientific understanding of how the human body works - of how it contracts, develops, resists, overcomes or succumbs to disease at the physiological and anatomical levels. I want my doctor to know all of this - and if necessary all of me - inside out. But let me suggest both how this can be built upon or augmented, and also how it can be subverted.

These days, the augmentation is actually pretty commonplace: namely, that clinical skills and competencies involve the ability to find out what is wrong with me, by examining me both physically and personally. By examining me 'personally', I mean here discovering and understanding what is individual about me, and how my individuality is necessary to treating me. These abilities are variously referred to as communication skills, narrative skills, skills of interpretation, interpersonal skills, ethical awareness and so on, and it seems sensible to suppose that a good (albeit guided) soaking in decent literature might offer anyone who wanted it an opportunity to enrich the abilities he or she already possessed.

In this context, McLellan observes that the skills of literary interpretation of texts help doctors consider 'the totality of the lives of patients they may meet only in limited, fragmented ways.' (McLellan, 1996: p. 110). Again, Charon tells us that the study of literary methods 'help[s] doctors and patients to achieve contextual understandings of singular human experiences' and that such study supports 'the recognition of multiple contradictory meanings of complex events' (Charon et al, 1996: p. 243 (my italics)).

Such capabilities obviously augment the biomedical knowledge expected of the doctor, but I think they can be seen in some ways as subverting that knowledge. This might seem like an over-statement, but medicine is part of the human endeavour of healing, and ought to be conceived in that light. Humans are not machines, and the ways in which we fall ill and our prospects for getting better are intensely influenced by the 'existential' questions, challenges and events in our lives. So 'examining me personally' (as distinct from examining me physically) is not simply a way of being efficient, speedy and courteous in getting at the somehow purely scientific information the doctor needs. 'Examining me personally' is the necessary way of getting the complete range of information relevant to the diagnosis, and not all of that information is well captured by biomedical science.

'Examining me personally' means finding out something of the salient facts of my 'case' as that 'case' feels to me - the person who lives the life in question. Why do I do what I do? Why are my ambitions and vulnerabilities what they are, and how do they bear on my tendency to get sick or stressed-out or flabby or dependent on an additional glass or two of wine - in the manner that is particular to me? Is my self-esteem appropriate and healthy? How do I see myself, my work, my relationships - do they inspire me or corrode me? And so on. And these are not determinate facts - by which I mean that they do not correspond to a tick in a box, or a block on a chart. They are perceptions - either held by me, or held about me by others and responded to by me. They are inter-personal, and in 
gathering some idea of them, the clinician herself enters an inter-personal connection with me in which her own perceptions become influential. Worse still, they are variables which are shockingly resistant to being controlled, and hence resistant to being understood or explored - still less experimented upon - within a biomedical model as ordinarily pictured. Whether, of course, we should allow the ordinary model of science to escape lightly with no acknowledgement of the personal and interpersonal dimensions of even simple experimental observation is another matter (Polanyi, 1958; Toulmin, 1993).

As I have elsewhere put the matter, the lives, experiences and understandings of the doctor and the patient can be thought of as two tracks across a world that is not by any means fully mapped out. Where those tracks cross, their different pasts and futures shape the way each understands the other. Their different understandings naturally supply and fix the images and metaphors each will use. Most intriguingly, the clinical encounter is a meeting of two uniquely embodied experiences, each of which has somehow to make sense of and respond to the other (Evans, 2002). Not only medical science, but also literature and history and philosophy and anthropology and psychology (among others), are at stake in understanding and describing that encounter.

Clinical medicine is both practically and (to my mind, as a layman) theoretically inseparable from the sorts of considerations which - when studied systematically - you would find in the disciplines of literature, history, ethics, philosophy, psychology and so forth. Properly understood, clinical medicine is an intervention in what might be called the existential world as well as in the natural world (Toulmin, 1993). I am frequently struck by the thought that some of the most remarkable features about our embodied human condition can be caught by acknowledging our carnal nature - the fact that we are meat - but also by then recognising (as the phenomenologist philosophers have long urged that we recognise) that our carnal nature is the ground and the form of our conscious experience and our understanding of ourselves - the fact, that is, that we are meat with a point of view (Evans, 2002).

Far more of our nature and situation is intensely physical than we are inclined to remember. I fear I am putting this point rather drily, as philosophers tend to do. It will be more real - as well as being more succulent - if I let the experience of one of classic literature's great characters, Konstantin Levin, put the point for me. Here, in a glowing passage from Anna Karenina (1876), Tolstoy describes Levin's unconscious sense of his own physicality and well-being as it emerges from the unaccustomed experience of mowing the ripe hay in the fields which he owns, but which he has hitherto never mown in the way that his peasant tenants mow them:

'In the very heat of the day, the mowing did not seem such hard work. The perspiration with which he was drenched cooled him, while the sun, that burned his back, his head and his arms bare to the elbow, gave a vigour and dogged energy to his labour; and more and more often now came those moments of oblivion, when it was possible not to think of what one was doing. The scythe cut of itself. Those were happy moments. Still more delightful were the moments when they reached the river at the end of the rows and the old man would rub his scythe with a thick knot of wet grass, rinse the steel blade in the fresh water of the stream, ladle out a little in a tin dipper, and offer Levin a drink.

"What do you say to my home-brew, eh? Good, eh?" he would say with a wink.

And truly Levin had never tasted any drink so good as this warm water with bits of grass floating in it and a rusty flavour from the tin dipper. And immediately after this came the blissful, slow saunter, with his hand on the scythe, during which he could wipe away the streaming sweat, fill his lungs with air, and look about at the long line of mowers and at what was happening around in the forest and the country.

The longer Levin mowed, the oftener he experienced those moments of oblivion when it was not his arms which swung the scythe but the scythe seemed to mow of itself, a body full of life and consciousness of its own, and as though by magic, without a thought being given to it, the work did itself regularly and carefully' (1954 reprint: p. 273).

Our sense of ourselves, our appearance, our capacities, our immediate movements, our place, our relations to others, the extent to which we are at ease in a given situation, our awareness of our surroundings, our expectations of what will happen to or around us in the next moment, our hopes, our plans, our hearts' desires, our terrors and dismay all of these have an intensely physical basis that it is often convenient to us to suppress or forget: but I think we are philosophically and psychologically and, indeed, clinically mistaken when we do so. And curiously - perhaps because in our paper-driven word-bound world we are rarely allowed so primarily physical an experience of ourselves and our surroundings as that enjoyed by Kostya Levin we are usually much better at remembering our physical nature when we are sick than when we are well. So clinical medicine is deeply driven by, and aims at modifying, our experiences of ourselves in sick or disabled or distressed states. It aims at intervening in our nature in order to relieve those experiences; it aims at an intervention in the point of view as well as in the meat. As such, clinical medicine inevitably has historical, philosophical, social, psychological and of course intensely literary 
dimensions, and these ways of looking at the people who present as patients are, I think, inescapably part of the clinical encounter - whether or not they are formally prepared for, or even recognised or acknowledged, by the clinician herself.

There are practical and, in a sense, moral objections to this enlarged picture of the clinical encounter, of course. Here, rehearsed very briefly, are five such objections. ${ }^{1}$ The personal and interpersonal aspects of the encounter may be what some patients fear or resent above all others; we ought not to assume that every patient is willing to be 'examined personally' any more than we can simply assume permission for a physical examination. Even granted such permission, we cannot know in advance what will be disclosed or what will be its implications: the clinical encounter may not be the best place to acknowledge the chaotic and destructive nature of some people's lives, although perhaps psychiatry above other specialisms steels itself to attempt that task. In the face of this, there is a sense of comfort, for the general clinician, in the retreat to a narrow physiological paradigm: from within its protection, the clinician can apparently more fairly ask of the patient: 'Just what is it you want from me?', and more reasonably refuse to offer, through medicine, any 'existential' guarantees about the patient's life and prospects. Simply preparing for medicine's personal dimension seems arduous - an enlarged specification for medicine seems only to add to the educational hurdles over which the unfortunate student must leap. Moreover, the personal dimensions of the clinical encounter are true for the clinician as well, whose embodied, carnal experience from time to time includes exhaustion, frustration and (in the ordinary sense) depression.

I am not going to address these objections directly, other than to acknowledge their force while yet insisting that they really show that clinical medicine's inevitably personal dimension is a tough, albeit rewarding, challenge for which medical education must do more to prepare tomorrow's doctors. My starting point is that the larger question of what medical knowledge actually is must finally be considered in these humanistic terms as well as in the more familiar scientific terms (Toulmin, 1993). So, therefore, is the deeply connected question of how that knowledge is to be gained. This then invites us to consider a wider range of medical educational 'goods' than simply the bio-scientific understanding of the body's physiological workings (Box 1).

What might these other 'goods' be? Allow me to suggest the following four, of which the first three

1. I am grateful to Heidi Lyth for pointing out to me the five objections here. are either explicit or implicit in the General Medical Council's landmark publication Tomorrow's Doctors (General Medical Council, 1993).

\section{Education, not training}

First, there is the emphasis upon education as distinct from training, and education moreover in an appropriately university-based medical curriculum. This perhaps requires a little elaboration. Certainly, this 'good' is not exclusive to medicine: quite the reverse, as Tomorrow's Doctors implicitly complained. Medical schools have consistently recruited very high-achieving school leavers, then processed them through an intensely demanding, even exhausting, scheme of study. But a scheme of study that involves the assimilation of a gigantic number of facts is unlikely to be - and traditionally has not been - a rewarding challenge to the creative intellect. Education is, among other things, an invitation to step through doors into larger 'rooms', conceived in imaginative, cultural, intellectual and (to use a risky word) spiritual terms - an invitation to step into those rooms, look around, and above all appraise for yourself what you find in them. This should form part of the study experience of any mature professional who will be engaged in a sophisticated inter-personal practice. It should be the cornerstone of developing the clinical professional's own personal resources for dealing with the uncertainties, even the chaos, of the demands of clinical life and the attitudes, behaviours, needs and goals of patients. A role in this for the study of literature is, I hope, readily apparent. Education consists in an enlargement of vision, and this enlarged vision is well served by the accomplishments of literary interpretation identified by Charon et al (1996) and McLellan (1996).

Box 1 Summary of the proposed objectives ('goods') of medical education

- A higher-educational experience of 'steps into larger rooms' - conceived in imaginative, cultural, intellectual and spiritual terms and not simply training

- The gaining of communication skills, including a sensitive appreciation of the ethical dimensions of practice

- The exploration, development and sustaining of the individual student's personal values

- The stimulation and encouragement of a fitting and enduring sense of wonder at embodied human nature 


\section{Ethics and communication skills}

The second educational 'good', and one which is perhaps rather more directly 'applied' to the clinical situation than was the first, is the development of medical students' communication skills, including (obviously) a sensitive appreciation of the ethical dimensions of their practice. As an intrinsically good thing, this second 'good' needs no further explanation. It also seems straightforward to suppose that the structured and studied interpretation of literary texts supports it, particularly in the terms Charon commends (Charon et al, 1996).

An objection sometimes raised in this context is that it is disreputable to 'use' literature (or, for that matter, any of the creative or expressive arts) in such an instrumental way - the arts should be pursued for their own sake, and not for the sake of what they can do for us (Pickering, 1998). I have some sympathy with this admittedly rather purist objection: it might be that, like humility, a capacity for sensitive interpretation is not something you can coldly and intentionally go out and get, although it might easily be the natural result of doing something else, namely approaching literary texts in the right spirit of seriousness and curiosity, and moreover doing so for their own sake. It is interesting that this objection seems not to apply to the study of other supposedly 'visiting' disciplines within the medical curriculum (such as psychology or philosophy or history), and reflects I think a special intimacy with which we engage literature and the - as it were - tender place we accord literature which we love.

The answer to the objection, in my view, lies in how we choose, present and explore the texts themselves: Mann's The Magic Mountain or Kafka's Metamorphosis are good examples of daunting texts which one might approach 'instrumentally', with anxiety and distaste, only to embrace them with passion and leave them tenderly: loving them for their own sake, perhaps not even noticing - until the time comes when it will really count - that one's awareness of the complexity and ethical sensitivity of situations and contexts is richer than it was.

\section{Developing personal values}

The third 'good' is that of encouraging students to identify, explore, develop and sustain their own personal values. It is not always easy to say exactly what we believe in or what our values are, even from the imagined vantage point of middle age and midcareer. How many of us in that position entirely recall the values we suppose ourselves to have held as youthful idealists, at the outset of our careers or our university degree courses? Did we graduate with a well-formed set of personal values - or did they accrete around us, accidentally, unplanned, as part of our ad hoc responses to the crises (personal or professional) that came our way? The traditional medical curriculum may have presumed some traditional professional values, but the habits of loyalty and the closing of ranks do not constitute a complete set of ethics, nor need they come naturally and authentically to every clinical practitioner facing the occasional clash of interests between patient and professional, or patient and institution. Such situations perhaps can never be properly prepared for - authentic moral life, I suspect, can never consist in complete preparation, but must always allow room for spontaneous reaction to the particularities of precisely this or that situation. Even so, it is better to have thought about what you believe in before you put your beliefs to the test, and it seems to me that this is one of the attitudes and facilities that we should try to develop in students of all disciplines: why not students of medicine, tomorrow's front-line clinical practitioners? And where better than in the comparative safety of the literary encounter to test, and extend, your range of beliefs and attitudes? As the Oxford Handbook of Clinical Specialties puts it:

\footnotetext{
'When we read alone and for pleasure, our defences are down - and we hide nothing from the great characters of fiction. In our consulting rooms, and on the ward, we so often do our best to hide everything, beneath the white coat, or the avuncular bedside manner. So often, a professional detachment is all that is left after all those years inured to the foibles, fallacies and frictions of our patients' tragic lives. It is at the point where art and medicine collide, that doctors can re-attach themselves to the human race and re-feel those emotions which motivate or terrify our patients ... [E]very contact with patients has an ethical and artistic dimension, as well as a technical one' (Collier et al, 1995: p. 413).
}

\section{A sense of wonder}

Fourth and finally, I suggest an educational 'good', which is not in fact implicit in Tomorrow's Doctors, but whose importance I think is implicit in the clinical encounter. It is not at all easy to express it: I would summarise it as the stimulation and encouragement of a fitting and enduring sense of wonder at embodied human nature. Let me try to say what I think this sense of wonder is or involves, and then say why it is important. The general idea of a sense of wonder is closely tied to curiosity, indeed, is probably the basis of some of our most important curiosity, driving the early investigations of the natural world and, I trust, the individual investigations carried on by many in science today. A sense of wonder is more than curiosity alone, however; it implies a kind of recognition of something's having 
special significance or even grandeur, so the recognition may sometimes amount to an attitude of awe or reverence. As such, a sense of wonder prompts reflective considerations about the place of mankind in the natural world and questions about whether 'the natural' is the sum total of the world, questions about what or who controls that world and about our individual destinies within it. Again, it would be hard to doubt that a sense of wonder has played a role in creative artistic responses to the world around us.

To approach something in wonder is to put yourself aside to some extent, to magnify the significance of the observed in relation to you who observe. The psychological importance of this is felt, for instance, when as a parent you contemplate your child; but also when you are struck by how experiences that you recognise in yourself belong also to other people - who, perhaps, respond to them as you would yourself like to respond to them (creatively, bravely, calmly, with insight) though you fear that in fact you could not. In this way, wonder is an important attitude ethically, reminding us that things, or people, or interests beyond ourselves are connected to us, but also have a claim upon us sometimes a higher claim than the mundane ones that normally see us through the working day. Literature peerlessly opens our eyes to wonder. I think the electrifying passage from The Magic Mountain with which I began exemplifies this perfectly, laying open to our gaze not only the literal but also the metaphorical wonder of our own physicality (Good God, it was the heart!... He looked into his own grave... the flesh in which he walked [was] disintegrated, annihilated, dissolved in vacant mist) in stunning yet sobering verbal apparitions.

Why is this clinically important? Those latter, ethical aspects are probably clearest, and apply quite straightforwardly to the praiseworthy list of 'attitudinal objectives' urged in Tomorrow's Doctors. To wonder at the fortitude of patients is, among other things, also to respect those patients. But a sense of wonder also invites us to incorporate gentleness, discretion, dignity and respect into that scientific curiosity which it is natural to feel towards so perplexing a phenomenon as the embodied, experiencing, human organism - who is also the patient. A lively and cultivated sense of wonder extends our capacity to be committed professionally to each successive individual, each particularised case of otherwise abstract and general disease categories and, moreover, stimulates a richly alert awareness of the diagnostic and therapeutic importance of easily missed variations in presentation and context. Above all, a sense of wonder wonder at this wondrous intersection, fusion, of 'meat' and 'point of view' - is the bedrock of recognising the medical privilege of intervening in frail human flesh and experience. Being aware of that privilege could brighten the darkest of clinical days in the course of a demanding career.

\section{References}

Charon, R., Brody, H., Clark, M. W., et al (1996) Literature and ethical medicine: five cases from common practice. Journal of Medicine and Philosophy, 21, 243-265.

Collier, J. A. B., Longmore, J. M. \& Hodgetts, T. J. (1995) Fame, fortune, medicine and art. In The Oxford Handbook of Clinical Specialities (4th edn) (eds J. A. B. Collier, J. M. Longmore \& T. J. Hodgetts), p. 413. Oxford: Oxford University Press.

Evans, M. (2002) Reflections on the humanities in medical education. Medical Education, 36, 506-507.

General Medical Council (1993) Tomorrow's Doctors: Recommendations on Undergraduate Medical Education. London: General Medical Council.

Mann, T. (1927) Der Zauberberg. Reprinted (1996) as The Magic Mountain (trans. H. Lowe-Porter). New York: Vintage Books.

McLellan, F. (1996) Why literature and medicine? Lancet, 348, 109-111.

Pickering, N. (1998) Imaginary restrictions. Journal of Medical Ethics, 24, 171-175.

Polanyi, M. (1958) Personal Knowledge: Towards a Post-critical Philosophy. Chicago, IL: University of Chicago Press.

Tolstoy, L. (1876) Anna Karenina. Reprinted (1954) as Anna Karenin (trans. R. Edmonds). Harmondsworth: Penguin.

Toulmin, S. (1993) Knowledge and art in the practice of medicine: clinical judgement and historical reconstruction. In Science, Technology and the Art of Medicine (eds C. Delkeskamp-Hayes \& M. A. Gardell Cutter), pp. 231-249. Dordrecht: Kluwer Academic Publishers.

\section{INVITED COMMENTARY ON Roles for literature in medical education}

I yield to no one in my regard for Advances in Psychiatric Treatment, but must admit that even in a journal of its quality, it is rare to find a paper that is an unalloyed joy to read. Evans's exploration of how literature can illuminate medical education was, for me, pure pleasure - to the extent that anyone watching me reading it for the first time might have concluded from my enthusiastic nods, smiles and 